\title{
ENHANCEMENT OF DISSOLUTION AND STABILITY OF CANDESARTAN CILEXETIL-LOADED SILICA POLYMERS
}

\author{
MAI KHANFAR ${ }^{1 *}$, BASHAR AL TAANI ${ }^{1}$, EMAN MOHAMMAD ${ }^{1}$
}

1*Department of Pharmaceutical Technology, Faculty of Pharmacy, Jordan University of Science and Technology, Irbid 22110-Jordan

Email: mskhanfar@just.edu.jo

Received: 23 Oct 2018, Revised and Accepted: 09 Jan 2019

\section{ABSTRACT}

Objective: To prepare stable amorphous solid dispersions of candesartan cilexetil (CAN) with different types of silica, including non-porous (aerosil 200) and porous silica (sylysia 350) using the spray-drying method.

Methods: various ratios of candesartan cilexetil (CAN) were spray dried with aerosil and sylysia. Powder x-ray diffraction (x-ray) differential scanning calorimetry (DSC), SEM were used to characterize the spray dried powders in addition to dissolution and stability studies.

Results: X-ray results showed that the spray-dried (CAN) in the prepared solid dispersion were in amorphous form irrespective of the used silica. In (DSC) analysis, the melting peak of spray-dried (CAN-silica) solid dispersion disappeared. Dissolution property of (CAN) was remarkably improved by formulating with silica particles. In comparing the effect of the type of the silica particles, the dissolution rate of (CAN) from the spraydried (CAN-sylysia) was faster than that (CAN-aerosil 200) irrespective of the drug content. It was also shown that the spray-dried formulation with silica did not recrystallize when storing at severe storage conditions $\left(40{ }^{\circ} \mathrm{C}, 75 \% \mathrm{RH}\right)$ for three months, while spray-dried (CAN) without silica easily re-crystallized under the same conditions.

Conclusion: Spray drying of (CAN) with sylysia 350 is an efficient method to enhance the dissolution and stability of the drug.

Keywords: Aerosil, Amorphous, Candesartan cilexetil, Solid dispersion, Spray-drying, Sylysia

(C) 2019 The Authors. Published by Innovare Academic Sciences Pvt Ltd. This is an open access article under the CC BY license (http://creativecommons.org/licenses/by/4.0/) DOI: http://dx.doi.org/10.22159/ijap.2019v11i2.30411

\section{INTRODUCTION}

Over recent decades, many poorly water-soluble drugs have been developed in the pharmaceutical field; this creates one of the most challenging issues for the pharmaceutical industry. Candesartan cilexetil (CAN) is an angiotensin II-receptor blocker (ARB) used in the treatment patients with hypertension, heart failure and diabetic nephropathy [1]. It has a low solubility in the gastrointestinal fluids, which can limit its therapeutic efficacy. Increasing (CAN) solubility can improve its bioavailability [2]. Dispersion of the drug as very fine particles will increase the surface area available for dissolution. According to the classical Noyes-Whitney equation, this will increase the dissolution rate [3] One way to increase the surface area to improve the dissolution rate is by reducing the particle size using micronization. Alternatively, the dissolution rate of (CAN) can be improved also by increasing its aqueous solubility through formation of a cyclodextrin inclusion complex [4] or through the preparation of self-micro emulsifying drug delivery systems (SMEDDS) [5-7] or by developing (CAN)-loaded solid lipid nanoparticles (CLNs) $[8,9]$ or through formation of solid dispersion involving effective P-gp inhibition (P-glycoprotein-which is an efflux pump distributed throughout the body especially in the intestinal epithelium, and is responsible for limiting cellular uptake and the distribution of xenobiotics by pumping any them back into the intestinal lumenfor optimal drug delivery $[10,11]$.

The disadvantages of the previous methods are the complexity of their preparation and the use of expensive excipients.

Another method for improving the dissolution is through amorphization and stabilization of the amorphous form in the drug product $[12,13]$. The amorphous form usually has higher apparent solubility and improved dissolution rate compared to the crystalline counterpart, but it is rarely used in pharmaceutical formulation due to its hygroscopicity and tendency to recrystallize [14]. Common methods for preparation of amorphous form can be divided into two categories namely; solvent evaporation based methods and nonsolvent based ones [15].
In the pharmaceutical industry, solvent evaporation based methods include: spray drying [5] in which the dry powder is produced from liquid solutions, suspensions or slurry by rapidly atomizing the liquid and drying using hot gas, freeze-drying [16] also known as lyophilization or cryodesiccation, is a dehydration process in which water is frozen in the sample and then removed by sublimation at low temperatures, in and rapid precipitation by anti-solvent which is a process in which solution of the drug and the carrier is prepared and then different solvent (anti-solvent) is added to the solution and because of the high difference in polarity between the two solvents both the drug and the carrier will precipitate in the antisolvent. Then the final suspension containing the drug and the carrier must be filtered or evaporated. The non-solvent preparation methods are either by melting and quench cooling in which the molten drug is cooled down below the melting point, the degree of cooling will determine the molecular order of the material, where fast cooling results in amorphous molecules, or by milling the drug using different milling techniques (ball milling or cryo-milling) [17], in which the material is loaded into a chamber having steel balls then a specific rotational speed is applied, this method is reported to transfer crystalline drugs to their amorphous form thus increasing dissolution rate [18].

Adsorption onto the surface of silica carriers is a known method for improvement of the dissolution rate of poorly soluble drugs. This was first described in the early 1970s [19]. Recently, some researchers have reported the production of solid dispersions of drugs using spray-drying in which they suggests that the drug may enter into the pore channels or adsorb onto the surface of a silica carrier [20-22]. Takeuchi et al. [23] reported that preparation of solid dispersion with silica carriers by spray-drying method could improve the dissolution rate of tolbutamide and stabilize metastable crystals in the solid dispersion particles under the severe storage conditions of high temperature and humidity $\left(60{ }^{\circ} \mathrm{C}, 75 \%\right.$ RH) [23]. Silica particles contain many silanol groups on their surface and can be used as a pharmaceutical excipient; they are regarded as safe for oral consumption [24]. Sylysia is amorphous silica $\left(\mathrm{SiO}_{2} \cdot \mathrm{nH}_{2} \mathrm{O}\right)$, synthetically produced, and micronized it is 
characterized by high porosity and chemical purity. The porous structure, high specific surface area, and the capacity of porous silica's adsorption will influence the drug dissolution rate and improve the stability of amorphous drugs [25]. While aerosil 200, is a nonporous material made of hydrophilic fumed silica (silicon dioxide) [24]

In this study, two successfully prepared amorphous solid dispersions of (CAN) one with porous silica (sylysia 350) and the other with nonporous silica (aerosil 200) were prepared by the spray-drying method. Comparisons of the release characteristics, physicochemical properties and stability of the two formulations were done. The effect of the silica ratio to the drug on the physicochemical properties and dissolution rate of the prepared dispersions was also studied.

\section{MATERIALS AND METHODS}

\section{Materials}

Candesartan cilexetil (CAN) was kindly donated by the Jordanian Pharmaceutical Manufacturing Company, Jordan. Two types of silica (aerosil 200, and sylysia 350, Fuji Chemical Ltd., Japan) were used as obtained. The properties of the carriers are shown in table 1. Methanol HPLC grade was obtained by Fisher, PA, America), polysorbate 20 (Tween 20 was obtained by ACROS Organics, Geel, Belgium), Deionized distilled water was used in all experiments. All chemicals and reagents were used as supplied without further modification and of analytical grade.

Table 1: Physicochemical properties of silica particle

\begin{tabular}{|c|c|c|c|c|c|}
\hline & Porosity & Particle size $(\mu \mathrm{m})^{*}$ & Specific surface area $\left(\mathrm{m}^{2} / \mathrm{g}\right)^{* *}$ & Pore size (nm) & Pore volume (ml/g) \\
\hline Aerosil 200 & non-porous & 0.012 & $2.0 \times 10^{2}$ & --------- & ------------ \\
\hline Sylysia350 & porous & 3.9 & $3.0 \times 10^{2}$ & 21.0 & 1.6 \\
\hline
\end{tabular}

${ }^{*}$ The values were with mean $\pm S D, n=3$, ${ }^{* *}$ The values were with mean $\pm S D, n=3$

\section{Preparation of solid dispersion particles}

The solid dispersion particles of (CAN) with silica were prepared using the spray-drying method. One gram of (CAN) was dissolved in $100 \mathrm{ml}$ of $35 \% \mathrm{v} / \mathrm{v}$ methanol in water (the solvent was prepared by adding water to $35 \mathrm{ml}$ of methanol until the final volume reach $100 \mathrm{ml}$ and then silica was added in different ratios $(1: 0,1: 1,1: 3$, $1: 5,1: 7)$.

After ultra-sonication for five minutes, the suspension was fed to Büchi mini spray dryer (Model B-190, Büchi LaboratoriumsTechnik, Flawil, Switzerland) at a rate of $5 \mathrm{ml} / \mathrm{min}$, the aspirator was set at 15 and the inlet and outlet temperatures of the drying chamber were maintained at 85 and $60{ }^{\circ} \mathrm{C}$, respectively.

All dispersions were subsequently passed through a 40-mesh screen $(425 \mu \mathrm{m})$ and stored in desiccators over silica gel until used for further analysis.

\section{Physicochemical characterization of solid dispersion particles}

The size of the solid dispersion particles was measured by Microtrac particle size analyzer (S3500, Montgomeryville, PA 18936, USA), 2400A, Tonichi Computer, Tokyo Japan). The particle shape was observed by scanning electron microscopy (Quanta 450 FEG-USA/EEU). The specific surface area of solid dispersion particles was also measured by the $\mathrm{N}_{2}$ adsorption method (Quanta Chrome NOVA series 2000, Japan) after degassing the sample powder for 12 h (Flow Prep060; Shimadzu Co., Japan).

The crystalline form of (CAN) in the solid dispersions was measured by powder X-ray diffraction method (Ultima IV X-ray diffractometer, Rigaku, Japan) and differential scanning calorimetry (DSC) (NETZSCH-DSC 204 F1 Phoenix with ASC, Japan). In DSC analysis, $0.5-1.0 \mathrm{mg}$ of sample powder was put in a crimped aluminum sample pan. The increasing rate of temperature was $10^{\circ} \mathrm{C} / \mathrm{min}$.

\section{Determination of the polymer adsorption capacity}

In order to study the silica adsorption capacity for (CAN) from methanol solution onto silica surface, $250 \mathrm{mg}$ of (CAN) was dissolved in $25 \mathrm{ml}$ of methanol. Then different silica (aerosil, sylysia) were suspended into the solution in 1:1 drug: silica ratio. The suspensions were stirred for $48 \mathrm{~h}$ and then centrifuged. Afterward the drug content was determined.

\section{Determination of the drug content}

The total amount of the loaded (CAN) was determined using UV9200 spectrophotometer (Rayleigh Analytical Instrument Corp.,
China). $25 \mathrm{mg}$ of each sample was added to $100 \mathrm{ml}$ of methanol as a solvent and sonicated for $15 \mathrm{~min}$, then three milliliters of the supernatant was filtered through $0.45 \mu \mathrm{m}$ cellulose nitrate membrane filter (Sartorius, Gottingen, Germany) and analyzed using UV-9200 spectrophotometer (Rayleigh Analytical Instrument Corp., China) at $\lambda$ max of $245 \mathrm{~nm}$.

\section{Determination of the drug loading efficiency (LE)}

The drug loading was determined depending on practical drug content previously measured and theoretical drug content that used in the preparation.

Drug loading efficiency $=\frac{\text { Practical drug content }}{\text { Theoritical drug content }} \times 100 \%$

The drug loading efficiency was calculated as \% drug loading according to the following equation.

\section{In vitro release study}

In vitro dissolution studies were performed using USP dissolution apparatus II (rotating paddle). This test was performed in $900 \mathrm{ml}$ of $0.05 \mathrm{M}$ phosphate buffer $(\mathrm{pH}=6.5)$ with $0.01 \%$ tween 20 in water at $37 \pm 0.5{ }^{\circ} \mathrm{C}$ and $50 \mathrm{rpm}[26]$.

At specific time intervals $(10,20,30,45$ and $60 \mathrm{~min})$ five $\mathrm{ml}$ samples were withdrawn, filtered using a $0.45 \mu \mathrm{m}$ cellulose nitrate membrane filter (Sartorius, Gottingen, Germany) and analyzed using UV-9200 spectrophotometer (Rayleigh Analytical Instrument Corp., China) at $\lambda$ max of $245 \mathrm{~nm}$.

The withdrawn samples were replaced by equal volumes of fresh buffer media. All experiments were done in triplicate. All dilutions are accounted for in measurements.

\section{Physical stability study}

In order to evaluate the effect of temperature and humidity, dispersions were placed in a $25 \mathrm{ml}$ vial and stored at $40{ }^{\circ} \mathrm{C} \pm 2{ }^{\circ} \mathrm{C}$ and $75 \% \pm 5 \%$ relative humidity in Schutzart-Memmert, Schwabach, Germany) stability chamber. After three months the crystalline form of (CAN) in solid dispersion particles was measured by powder X-ray diffraction method (Ultima IV X-ray diffractometer, Rigaku, Japan) and differential scanning calorimetry (NETZSCH-DSC 204 F1 Phoenix with ASC, Japan).

\section{RESULTS AND DISCUSSION}

Table 2 shows the average particle size of spray-dried (CAN) and spray-dried (CAN-sylysi) and spray-dried (CAN-aerosil) solid dispersions. 
Table 2: Particle size of solid dispersion particles with Aerosil 200 or Sylysia

\begin{tabular}{llll}
\hline Sample & CAN (raw) & Spray-dried CAN & CAN-aerosil 200 \\
\hline $\begin{array}{l}\text { Particle size } \\
(\mu \mathrm{m}) \text { D50 }\end{array}$ & $51.6 \pm 5.2$ & $37.2 \pm 3.4$ & $19.5 \pm 8.3$ \\
\hline
\end{tabular}

Values with mean $\pm S D, n=3$.

The size of all spray-dried (CAN), (CAN-sylysia) and (CAN-aerosil) solid dispersion was smaller than that of raw (CAN) indicating that the technique of spray drying have a large impact on decreasing particle size, The size of spray-dried (CAN-aerosil) is noticed to be larger than spray-dried (CAN-sylysia), this is could be due to many factors, firstly, sylyia although have larger particle size than aerosil, it has higher surface area $\left(269 \mathrm{~m}^{2} / \mathrm{g}\right.$ compared with $\left.230 \mathrm{~m}^{2} / \mathrm{g}\right)$, but after spray drying, it was noticed from table 2 that particle size of sprayed-dried (CAN-sylysia) is the smallest compared with spraydried (CAN) and spray dried (CAN-aerosil) which is also aid in enhancing dissolution as decreasing particle size, increase surface area subjected to dissolution. The difference in surface area alone cannot account for differences in dissolution, the second major factor is the porosity of sylysia,due to the high porosity of sylysia, the drug was entrapped inside the pores to be ready for dissolution which is evidenced in table 2 where the surface area of spray-dried (CAN-sylysia) decreased from $\left(269 \mathrm{~m}^{2} / \mathrm{g}\right.$ to $\left.93.1 \mathrm{~m}^{2} / \mathrm{g}\right)$ indicating loss of area due to more entrapment of the drug inside the pores, while the decrease in the surface area of spray dried (CAN-aerosil) from $\left(230 \mathrm{~m}^{2} / \mathrm{g}\right.$ to $\left.171 \mathrm{~m}^{2} / \mathrm{g}\right)$ indicating less of drug loading to the carriers. Similar results were observed for tolbutamide solid dispersion with different silica particles (sylysia 350 and aerosil 200) prepared by the spray-drying method [23]. Table 3 shows the drug loading inside both carriers with different ratios of drug to carrier. It is observed that as the ratio of the carrier increased, the drug loading increase using both carriers, but it is noticed also that drug loading inside sylysia is much higher than inside aerosil which is also expected considering the porosity of sylysia.

Table 3: Loading efficiency of the different silica polymers

\begin{tabular}{llll}
\hline Formula & Polymer used & Drug ratio & Average drug loaded in the dispersion \pm SD\% ( $^{*}$ ) \\
\hline SA1 & aerosil@200 & $1: 1$ & $49.5843 \pm 1.6113$ \\
SA3 & aerosil@200 & $1: 3$ & $25.4210 \pm 0.2510$ \\
SA5 & aerosil@200 & $1: 5$ & $16.9287 \pm 0.51331$ \\
SA7 & aerosil@200 & $1: 7$ & $14.0939 \pm 0.5562$ \\
SS1 & sylysia® 350 & $1: 1$ & $50.0607 \pm 1.6375$ \\
SS3 & sylysia@ 350 & $1: 3$ & $23.7416 \pm 0.3320$ \\
SS5 & sylysia@ 350 & $1: 5$ & $16.0473 \pm 0.2501$ \\
SS7 & sylysia® 350 & $1: 7$ & $12.9624 \pm 0.1444$ \\
\hline
\end{tabular}

*values with mean $\pm \mathrm{SD}, \mathrm{n}=3$

The scanning electron microscope (SEM) images of different dispersions are shown in (fig. (1) in the physical mixture for both types of silica carriers drug crystals can be clearly seen, while in the case of spray-dried dispersions, the images provide an evidence on the adsorption of the drug molecules on the surface of the carrier particles, which led to the destruction of the drug's crystallinity, so no crystalline drug was detected but rather more scattered drug molecules adsorbed on the surface of the carrier particles, which suggest that the drug is dispersed in its amorphous form.

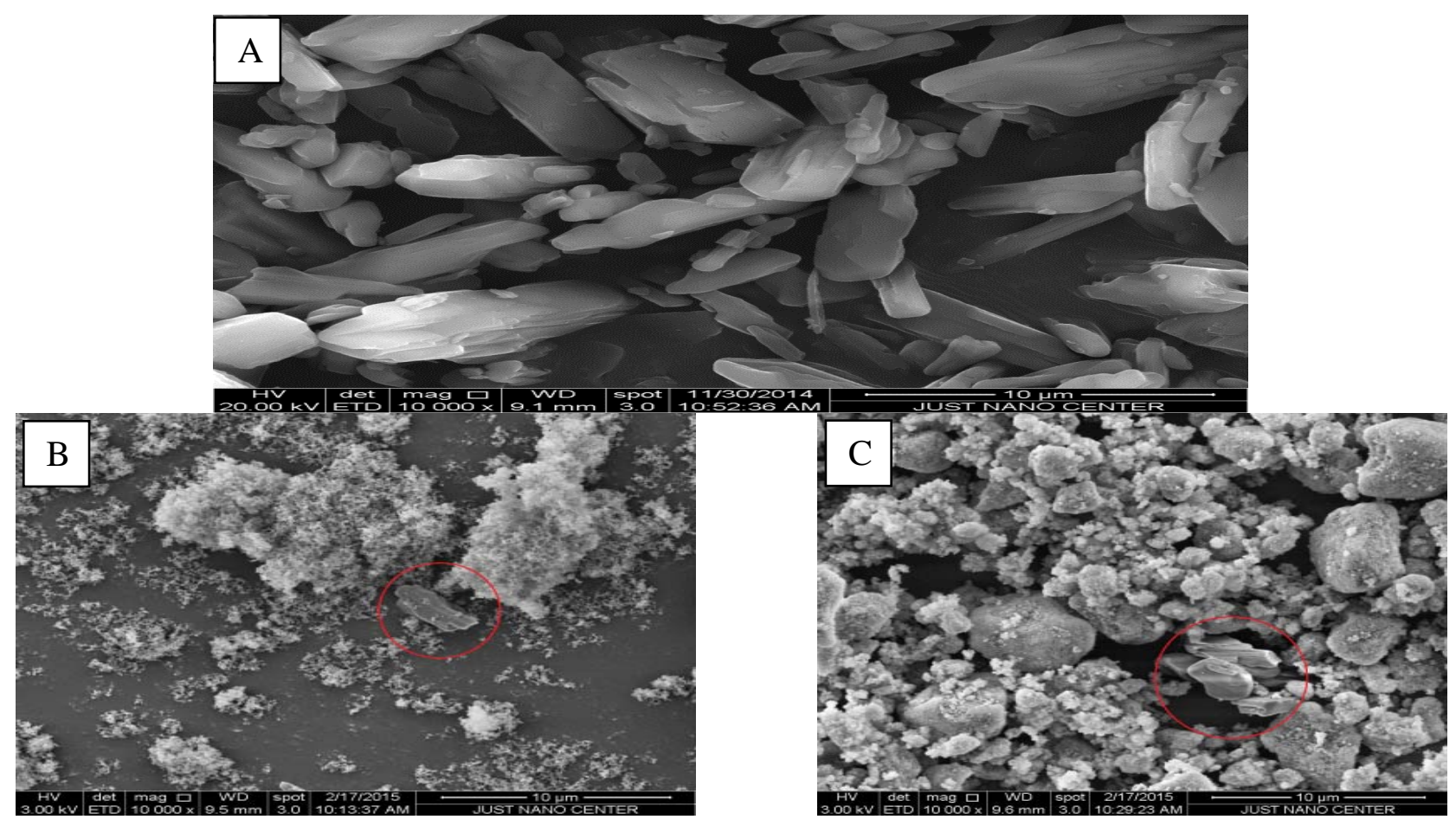



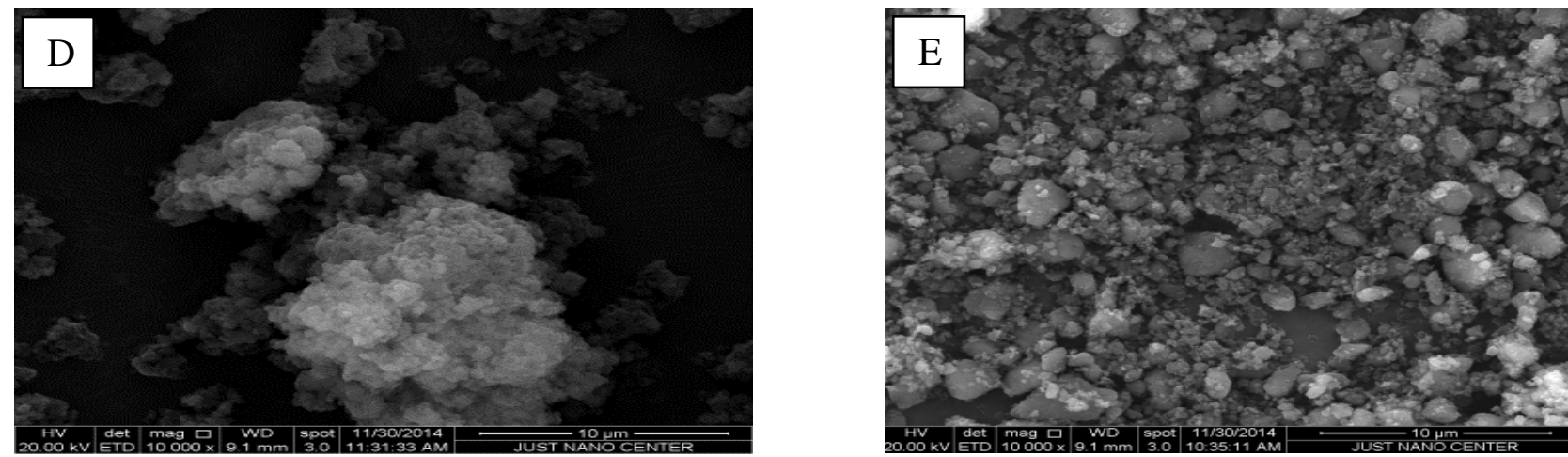

Fig. 1: SEM of different dispersions of CAN with sylysia and aerosil at $10000 \mathrm{X}$ power of magnification where (A) represents CAN (B) physical mixture of CAN: aerosil (C) physical mixture of CAN: sylysia 350 (D) spray-dried CAN: aerosil 200 (E) spray dried CAN: sylysia 350

The powder X-ray diffraction analysis in fig. (2) and (3) clarified that the raw which is the (CAN) used as supplied without any treatment-is in the crystalline form with high-intensity diffraction peaks between 5 and 25 (2-theta), while the spray-dried (CAN) was converted into the amorphous form. The change in the crystallinity of spray-dried (CAN)

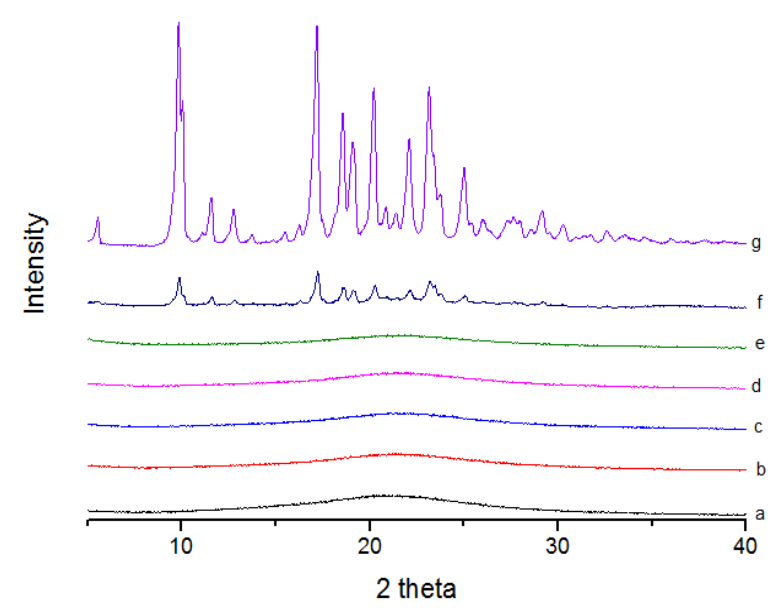

Fig. 2: X-Ray diffraction of solid dispersions containing aerosil@200 with different ratios (a)1:1(b)1:3(c)1:5(d)1:7(e) amorphous CAN(f) physical mixture with (1:5) ratio and (g) crystalline CAN

Many authors reported an interaction between drug molecules and silanol group of silica particles [23, 27-30]. In these reports, it was suggested that hydrogen bonding was formed between the silanol groups on the surface of silica with the carbonyl group of (CAN) drug. In the case of porous silica (sylysia 350) and (CAN), the hydrogen bonding was assumed to be formed in the pores of sylysia and the drug molecules were entrapped there which was evidenced by the SEM micrographs where the drug was entrapped inside in addition to the surface area of data of spray-dried conjugates. This ensures good dispersion of the drug in the solid dispersion particles.

DSC thermograms of raw, spray-dried (CAN) in addition to spraydried (CAN-aerosil) dispersions are shown in fig. (4). While those spray-dried dispersions of (CAN-sylysia) are shown in fig. (5). In both fig. the endothermic melting point of (CAN) which is expected to appear at $172{ }^{\circ} \mathrm{C}$ is absent, confirming the presence of the drug in its amorphous form as observed in the powder X-ray results. Similar findings were obtained by Shital Jondhale, et al. when they used the spray drying technique to produce amorphous dispersions of gliclazide with aerosil ${ }^{\circledR} 200$ or sylysi 350 [31].

For studying the effect of loading of the drug on the release of (CAN) from different spray-dried solid dispersions, dissolution tests were done. was probably because of the rapid drying rate from the drug solution. On the other hand, spray-dried (CAN) in solid dispersion prepared with silica shows a halo pattern without notable diffraction peaks indicating that (CAN) is in the amorphous form irrespective of the type of silica used in the formulation of the drug conjugates.

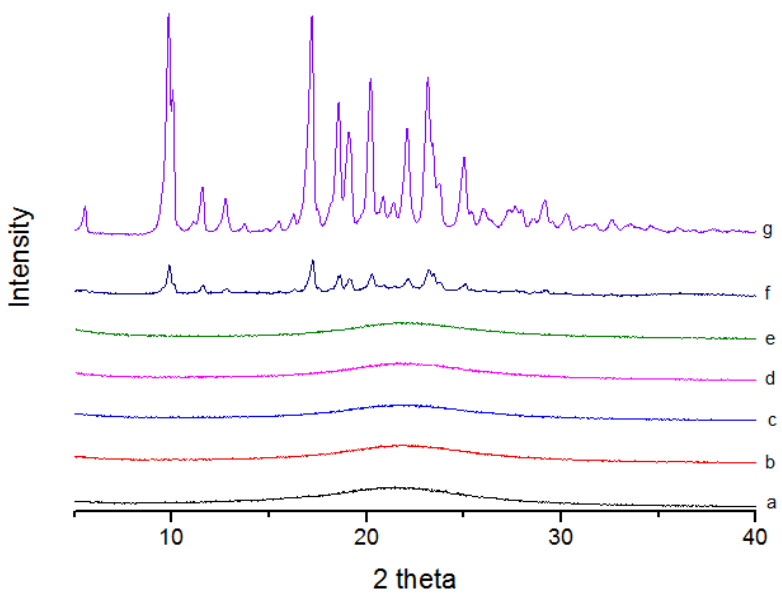

Fig. 3: X-Ray diffraction of solid dispersions containing sylysia ${ }^{\circledR} 350$ with different ratios

(a)1:1(b)1:3(c)1:5(d)1:7(e)amorphous CAN(f) physical mixture with $(1: 5)$ ratio and $(g)$ crystalline CAN

Fig. (6) and (7) show the dissolution profile of spray-dried (CANaerosil) dispersions and spray-dried (CAN-sylysia) dispersions respectively. By comparing the release of spray-dried (CAN) from both carriers (sylysia and aerosil), it was found that the release of (CAN) from silica carriers in the spray-dried solid dispersions was remarkably higher than spray-dried (CAN) alone irrespective of the used silica type. This can be attributed to the improvement in wettability and dispersibility of the drug in the dissolution medium as well as the decrease in particle size and the change of the drug from crystalline to amorphous form and it confirms that spraydrying of the drug alone did not give satisfactory release.

By comparing the dissolution profiles of solid dispersion prepared with aerosil 200 and sylysia 350, it was found that the release of (CAN) from spray-dried (CAN-sylysia) solid dispersions was slightly faster than the release of (CAN) from spray-dried (CAN-aerosil). This difference may be due to the larger specific surface area of sylysia ${ }^{\circledR}$ 350 since it is a porous polymer, having smaller particle size as indicated in table (2), where the particle size of spray dried (CANsylysia) is $(16.7 \pm 3.9 \mu \mathrm{m})$, while spray dried (CAN-aerosil) particle size is $(19.5 \pm 8.3 \mu \mathrm{m})$. The larger surface area will increase the carrier adsorption capacity of the drug. The same trend was seen in the release of lovastatin using different silica polymers where the release from sylysia showed the best release compared with other 
silica polymers which were explained due to the highest surface area leading to more wetting of the drug and hindering the

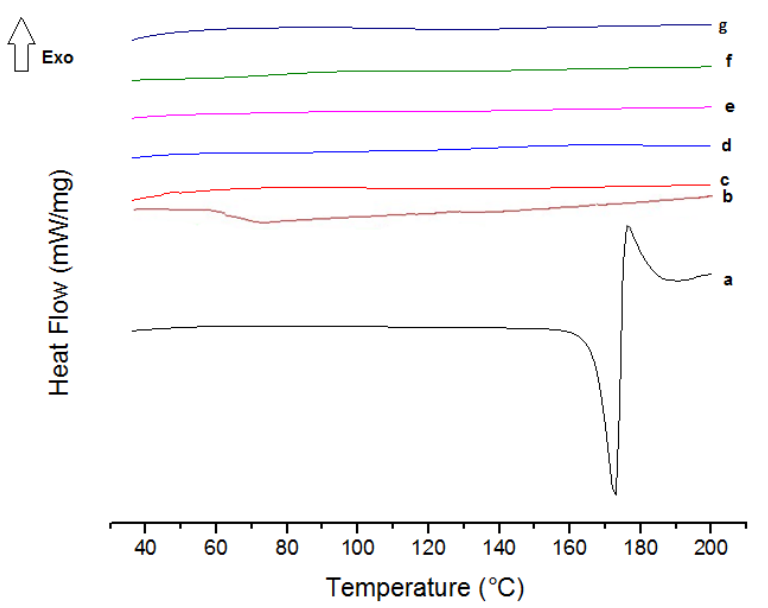

Fig. 4: DSC thermogram of (a) raw CAN (b) amorphous CAN and solid dispersions containing Aerosil@200 with different ratios (c)1:1(d)1:3(e)1:5(f)1:7 and (g) aerosil ${ }^{\circ} 200$

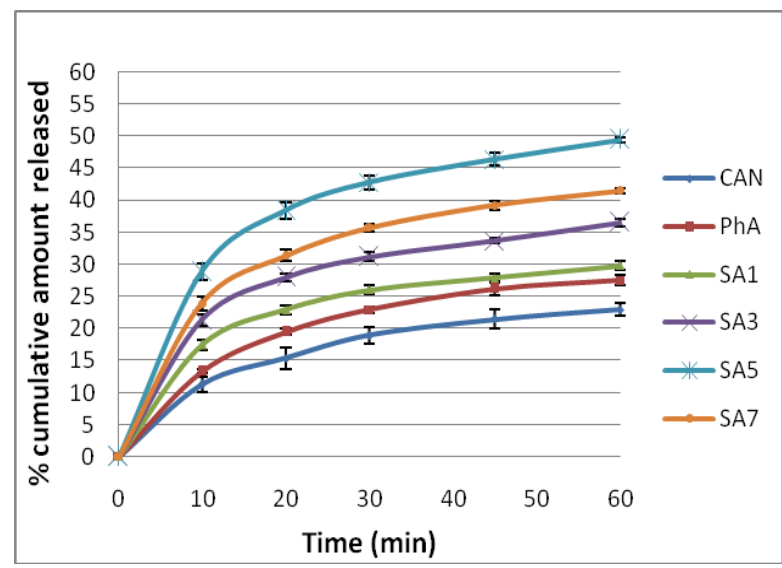

Fig. 6: Release profile of CAN, the solid dispersions containing aerosil@200 SA1 (1:1), SA3 (1:3), SA5 (1:5), SA7 (1:7) and the corresponding physical mixture with $(1: 5)$ ratio

There is a difference between the two silica types when used as a carrier in their effect in the dissolution profile. In case of aerosil 200, the change in the dissolution profile was small when changing the drug content, and it shows a slower dissolution rate than that of sylysia 350 at any drug content. On the other hand, the dissolution profile of solid dispersion prepared with sylysia 350 was faster irrespective of drug content. It can be concluded that sylysia 350 was better as a carrier to improve the dissolution property of (CAN) compared with aerosil 200.

It is well known that amorphous drugs formulated in the form of solid dispersion tend to recrystallize on storage at high temperature and humidity. Therefore, the effect of aging on the performance of amorphous (CAN) was investigated by performing accelerated stability studies up to three months as per ICH guidelines instructions [33].

It has been documented that the temperature during storage influences the rate of recrystallization process from amorphous to crystalline state. Humidity during the storage period is another important factor affecting the re-crystallization process. The plasticizing effect of absorbed moisture can permit a relatively rapid conversion to the crystalline form due to the high mobility of the amorphous form leading to further instability. Thus, appropriate transformation of the amorphous drug to the less soluble crystalline one [32].

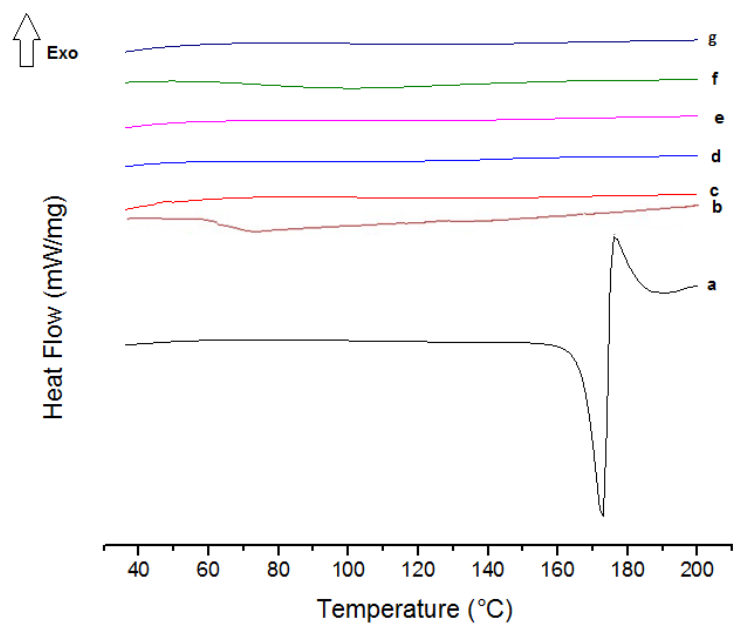

Fig. 5: DSC thermogram of (a) raw CAN (b) amorphous CAN and solid dispersions containing sylysia ${ }^{\circledR} 350$ with different ratios (c)1:1(d)1:3(e)1:5(f)1:7 and (g) sylysia ${ }^{\circledR} 350$

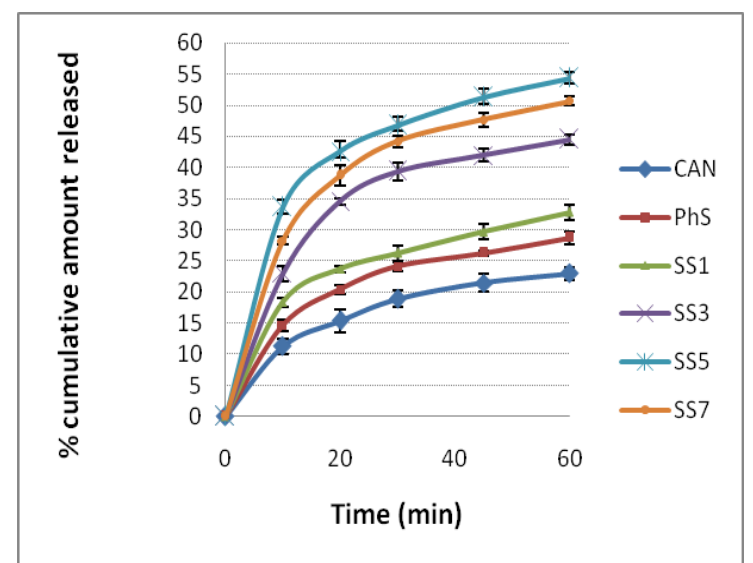

Fig. 7: Release profile of CAN, the solid dispersions containing sylysia ${ }_{\circledR} 350$, SS1 (1:1), SS3 (1:3), SS5 (1:5), SS7 (1:7) and the corresponding physical mixture with $(1: 5)$ ratio

storage conditions (aging) were selected during accelerated stability studies to be $40{ }^{\circ} \mathrm{C} / 75 \% \mathrm{RH}$.

To test the stability of amorphous (CAN) prepared by spray drying method, differential scanning calorimetry (DSC) and powder X-ray diffraction analysis were carried out for all amorphous dispersions after they were stored at $40{ }^{\circ} \mathrm{C}$ and $75 \%$ humidity for three months. fig. (8) and (9) show the DSC results for dispersions prepared with aerosil ${ }^{\circledR} 200$ and sylysia ${ }^{\circledR} 350$, respectively.

It is obvious from (fig. (8) that solid dispersions prepared with aerosil ${ }^{\circledR} 200$ are stable at high silica ratio while the dispersions containing $1: 1$ or $1: 3$ show an exothermic peak near $172{ }^{\circ} \mathrm{C}$ after the storage period which indicate that the amorphous form of the drug was recrystallized and transferred into a more thermodynamically stable form with lower dissolution properties.

This could be attributed to larger particle size and non-porous characteristics of aerosil which necessitate a higher amount of carrier to protect the drug and keep it in the amorphous form. While DSC thermograms of solid dispersions prepared with sylysia ${ }^{\circledR} 350$ after storage for three months demonstrate instability at 1:1 ratio; otherwise all dispersions were stable during the storage period as shown in fig. (9). 
These results were further confirmed by X-ray analysis as seen in (fig. (10) and (11), the observations were inconsistent with DSC results, where for aerosil ${ }^{\circledR} 200$, the dispersions containing $1: 1$ or $1: 3$

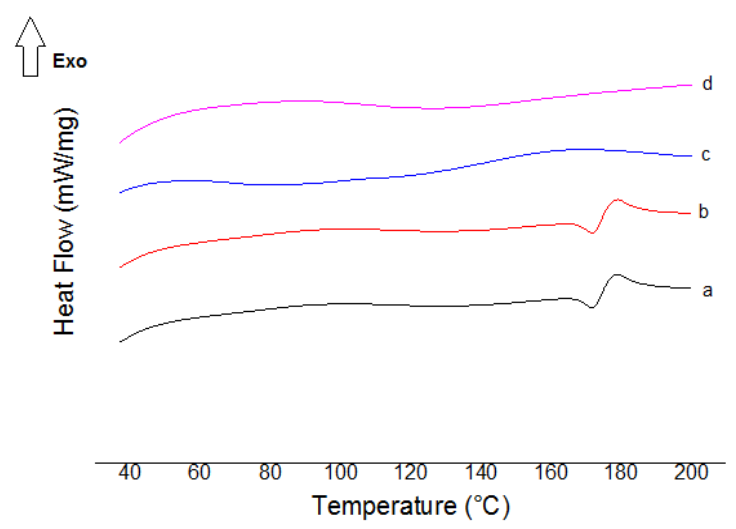

Fig. 8: DSC thermograms of amorphous solid dispersions containing aerosil@200, (a) SA1 (1:1), (b) SA3 (1:3), (c) SA5 (1:5), (d) SA7 (1:7) after storage for three months in the stability chamber

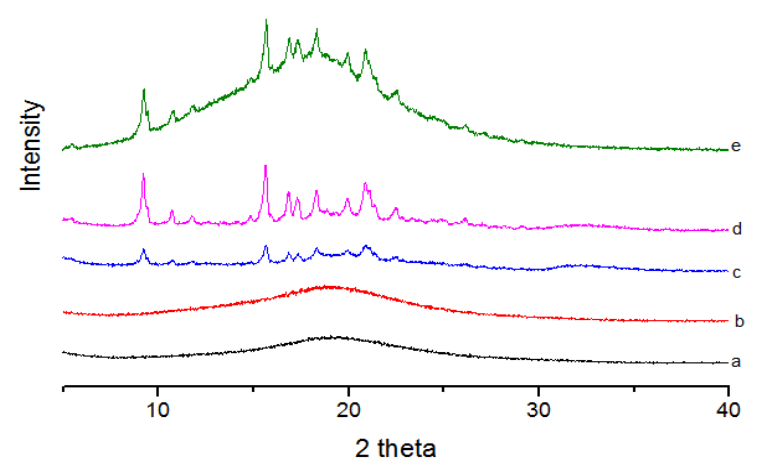

Fig. 10: X-Ray diffraction of solid dispersions containing aerosil@200, (a) SA7 (1:7), (b) SA5 (1:5), (c) SA3 (1:3), (d) SA1 (1:1) and (e) amorphous CAN without silica after storing all samples for $3 \mathrm{mo}$ in the stability chamber

Compared with the amorphous spray-dried (CAN) without silica, the X-ray curve shows the high intensity of diffractive peaks that attributed to the faster crystallization process of the drug.

\section{CONCLUSION}

Solid dispersion particles of (CAN) with different silica carriers were prepared using a spray drying method. The drug crystals were successfully transformed into the amorphous form and an improvement in the dissolution rate was achieved. Comparison of the dissolution rate and release of CAN between spray-dried (CANaerosil) and spray-dried (CAN-sylysia) it was found that the release of CAN from a dispersion prepared with sylysia ${ }^{\circledR} 350$ was faster than dispersions prepared with aerosil ${ }^{\circledR 2} 20$ irrespective to drug-silica ratio. Solid dispersions with high silica content were able to stabilize amorphous CAN even under severe conditions for three months.

\section{ACKNOWLEDGMENT}

The authors acknowledge the financial support provided by Jordan University of Science and Technology, grant number (132/2014).

\section{AUTHORS CONTRIBUTIONS}

All authors have contributed equally

\section{CONFLICTS OF INTERESTS}

The author declares no conflict of interest show some diffractive peaks indicating the instability of the amorphous drug, while for sylysia ${ }^{\circledR} 350$ dispersions only the dispersion with 1:1 ratio were unstable.<smiles>[R18]=C1CC1</smiles>
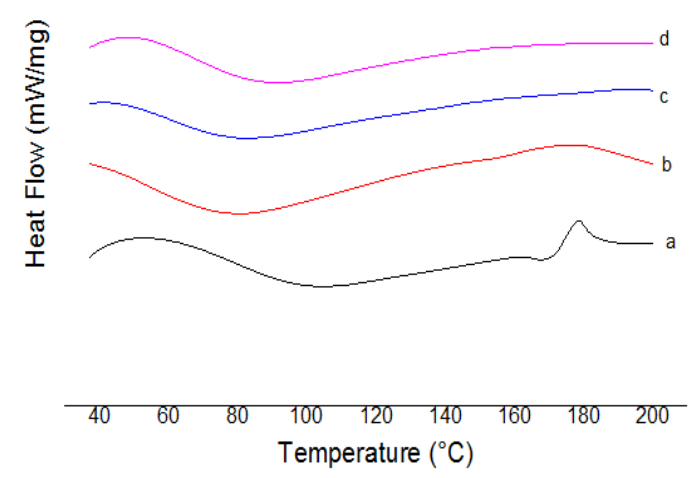

Fig. 9: DSC thermograms of amorphous solid dispersions containing sylysia ® 350, (a) SS1 (1:1), (b) SS3 (1:3), (c) SS5 (1:5), (d) SS7 (1:7) after storage for three months in the stability chamber

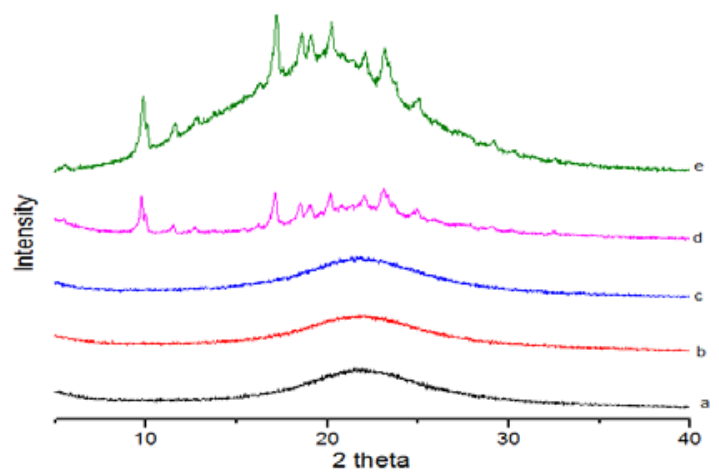

Fig. 11: X-Ray diffraction of solid dispersions containing sylysia ${ }^{\circledR} 350$, (a) SS7 (1:7), (b) SS5 (1:5), (c) SS3 (1:3), (d) SS1 (1:1) and (e) amorphous CAN after storing all samples for 3 mo in the stability chamber

\section{REFERENCES}

1. Easthope SE, B Jarvis. Candesartan cilexetil: an update of its use in essential hypertension. Drugs 2002;62:1253-87.

2. Shaikh SM, AM Avachat. Enhancement of solubility and permeability of candesartan cilexetil by using different pharmaceutical interventions. Curr Drug Delivery 2011; 8:346-53.

3. Noyes AA, WR Whitney. The rate of solution of the solid substance in their own solution. J Am Chem Soc 1897;19:930-4.

4. Al Omari, AA MM Al Omari, AA Badwan, KA Al-Souod. Effect of cyclodextrins on the solubility and stability of candesartan cilexetil in solution and solid state. J Pharm Biom Anal 2011;54:503-9.

5. Nekkanti V, P Karatgi, R Prabhu, R Pillai. Solid selfmicroemulsifying formulation for candesartan cilexetil. AAPS PharmSciTech 2010;11:9-17.

6. Abd Alhammid NS. Enhancement of the solubility and the dissolution rate of candesartan cilexetil using microsponge technology. Asian J Pharm Clin Res 2018;11:385-90.

7. Shukla KJ Girish, O Abdel Wahab. Formulation and evaluation of oral self microemulsifying drug delivery system of candesartan cilexetil. Int J Pharm Pharm Sci 2016;8:238-43.

8. Zhang, Z, F Gao, H Bu, J Xiao, Y Li. Solid lipid nanoparticles loading candesartan cilexetil enhance oral bioavailability: in vitro characteristics and absorption mechanism in rats. Nanomedicine 2012;8:740-7. 
9. Mahajan A, S Kaur, S Kaur. Design, formulation, and characterization of stearic acid-based solid lipid nanoparticles of candesartan cilexetil to augment its oral bioavailability. Asian J Pharm Clin Res 2018;11:7.

10. Surampalli G, BK Nanjwade, PA Patil, R Chilla. Novel tablet formulation of amorphous candesartan cilexetil solid dispersions involving p-gp inhibition for optimal drug delivery: in vitro and in vivo evaluation. Drug Delivery 2016;23:2124-38.

11. Amin ML. P-glycoprotein inhibition for optimal drug delivery. Drug Target Insights 2013;7:27-34.

12. Babu NJ, A Nangia. Solubility advantage of amorphous drugs and pharmaceutical cocrystals..Cryst Growth Des 2011; 11:2662-79.

13. Raghad AN, EZ Hind. Enhancement of candesartan cilexetil dissolution rate by using different methods. Asian J Pharm Clin Res 2015;8:320-6.

14. Hancock BC, G Zografi. Characteristics and significance of the amorphous state in pharmaceutical systems. J Pharm Sci 1997;86:1-12

15. Yu L. Amorphous pharmaceutical solids: preparation, characterization and stabilization. Adv Drug Delivery Rev 2001;48:27-42.

16. Craig DQM, PG Royall, VL Kett, ML Hopton. The relevance of the amorphous state to pharmaceutical dosage forms: glassy drugs and freeze-dried systems. Int J Pharm 1999;179:179-207.

17. Prakash K, R Jieun, K Hyeongmin, K ksoo, T Jeong, K Hyunil, et al. Pharmaceutical particle technologies: an approach to improve drug solubility, dissolution and bioavailability. Asian J Pharm Sci 2015;10:363-458.

18. Lim AW, K Löbmann, H Grohganz, T Rades, $N$ Chieng. Investigation of physical properties and stability of indomethacin-cimetidine and naproxen-cimetidine coamorphous systems prepared by quench cooling, coprecipitation and ball milling. J Pharm Pharmacol 2016;68:36-45.

19. Monkhouse DC, JL Lach. Use of adsorbents in the enhancement of drug dissolution. J Pharm Sci 1972;61:1430-5.

20. Takeuchi H. Solid dispersion particles of amorphous indomethacin with fine porous silica particles by using the spray-drying method. Int J Pharm 2005;293:155-64.

21. Planinsek O, B Kovacic, F Vrecer. Carvedilol dissolution improvement by preparation of solid dispersions with porous silica. Int J Pharm 2011;406:41-8.
22. Detroja C, S Chavhan, K Sawant. Enhanced antihypertensive activity of candesartan cilexetil nanosuspension: formulation, characterization and pharmacodynamic study. Sci Pharm 2011;79:635-51.

23. Takeuchi H, S Nagira, H Yamamoto, Y Kawashima. Solid dispersion particles of tolbutamide prepared with fine silica particles by the spray-drying method. Powder Technol 2004;141:187-95.

24. Bergna HE, WO Roberts. Colloidal silica: fundamentals and applications. CRC Press; 2005. p. 944.

25. Miura H, M Kanebako, H Shirai, H Nakao, T Inagi, K Terada. Enhancement of dissolution rate and oral absorption of a poorly water-soluble drug, k-832, by adsorption onto porous silica using supercritical carbon dioxide. Eur J Pharm Biopharm 2010;76:215-21.

26. United states pharmacopoeia. 31 ed. Rockville, USA: United States Pharmacopoeial Convention Inc; 2007.

27. Takeuchi H, T Handa, Y Kawashima. Spherical solid dispersion containing amorphous tolbutamide embedded in enteric coating polymers or colloidal silica prepared by spray-drying technique. Chem Pharm Bull 1987;35:3800-6.

28. Watanabe T, S Hasegawa, N Wakiyama, A Kusai, M Senna. Comparison between polyvinylpyrrolidone and silica nanoparticles as carriers for indomethacin in a solid state dispersion. Int J Pharm 2003;250:283-6.

29. Watanabe T, S Hasegawa, N Wakiyama, A Kusai, M Senna. Prediction of apparent equilibrium solubility of indomethacin compounded with silica by $13 \mathrm{c}$ solid-state $\mathrm{nmr}$. Int J Pharm 2002;248:123-9.

30. Watanabe T, N Wakiyama, F Usui, M Ikeda, T Isobe, M Senna. Stability of amorphous indomethacin compounded with silica. Int J Pharm 2001;226:81-91.

31. Jondhale S, S Bhise, Y Pore. Physicochemical investigations and stability studies of amorphous gliclazide. AAPS PharmSciTech 2012;13:448-59.

32. Khanfar M, S Al-Nimry. Stabilization and amorphization of lovastatin using different types of silica. AAPS PharmSciTech 2017;18:2358-67.

33. Laitinen R, K Lobmann, CJ Strachan, H Grohganz, T Rades. Emerging trends in the stabilization of amorphous drugs. Int J Pharm 2013;453:65-79. 